\title{
A Study on Rupture Uterus
}

\author{
Sanghamitra Mohapatra ${ }^{1}$, Nishitha Thanikkal ${ }^{2}$
}

${ }^{1}$ Associate Professor, Department of Obstetrics and Gynaecology, MKCG Medial College, Berhampur, Odisha, India. ${ }^{2} 2^{\text {nd }}$ Year Junior Resident, Department of Obstetrics and Gynaecology, MKCG Medial College, Berhampur, Odisha, India.

\section{ABSTRACT}

\section{BACKGROUND}

Rupture uterus is a life-threatening obstetric complication with serious maternal and foetal side effects. The most common risk factor is previous uterine surgeries. Incidence is $0.3 / 1000$ to $7 / 1000$ deliveries in India. According to WHO, incidence is 5.35 per 10000 live births. It accounts for $5-10 \%$ of maternal deaths. Uterine rupture is associated with clinically significant uterine bleeding, foetal distress, expulsion or protrusion of foetus, placenta or both into abdominal cavity and the need for laparotomy and prompt delivery of the baby, uterine rent repair, or hysterectomy.

\section{METHODS}

This study of rupture uterus was conducted over a period of 1 year from June 2017 to May 2018, in the department of Obstetrics and Gynaecology, MKCG Medical College, Berhampur, Odisha. All cases of rupture uterus, who were referred from periphery or who developed this complication in this hospital, were included in the study.

\section{RESULTS}

Uterine rupture is one of the most catastrophic complications in obstetrics. Its incidence varies from $0.1 \%$ to $2.5 \%$ in different countries. The incidence of uterine rupture in our centre was $0.57 \%$. Previous caesarean section accounted for $74.14 \%$ of uterine rupture, that too in the lower segment (93.10\%). Subtotal/total hysterectomy was done in $68.97 \%$ cases and $31.03 \%$ cases were repaired. The maternal mortality was $5.17 \%$. Perinatal mortality was $94.83 \% .5 .17 \%$ of cases were live birth, as these cases were accurately diagnosed, and prompt and timely management was initiated.

\section{CONCLUSIONS}

Uterine rupture is a catastrophic but preventable complication. Reducing the primary caesarean section rate and optimising care for women with previous caesarean section will definitely decrease the incidence of rupture uterus. More vigilant approach to prevent obstructed and prolonged labour, use of partograph, high index of suspicion and quick referral to a well-equipped centre are some of the factors that can help in reducing the incidence of rupture uterus.

\section{KEY WORDS}

Uterine Rupture, Previous Caesarean, Pantograph
Corresponding Author: Nishitha Thanikkal, $2^{\text {nd }}$ Year Junior Resident, Department of Obstetrics and Gynaecology, MKCG Medical College,

Berhampur-760004, Odisha, India.

E-mail: drsushreesmita98@gmail.com

DOI: $10.14260 / \mathrm{jemds} / 2019 / 556$

Financial or Other Competing Interests: None.

How to Cite This Article:

Mohapatra S, Thanikkal N. A study on rupture uterus. J. Evolution Med. Dent. Sci. 2019;8(32):2554-2557, $10.14260 /$ jemds $/ 2019 / 556$

Submission 20-03-2019, Peer Review 25-07-2019, Acceptance 01-08-2019, Published 12-08-2019.

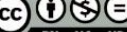




\section{BACKGROUND}

Rupture uterus is a life-threatening obstetric complication with serious maternal and foetal side effects. The most common risk factor is previous uterine surgeries. Incidence is $0.3 / 1000$ to $7 / 1000$ deliveries in India( ${ }^{(1)}$ and the perinatal mortality is as high as 74 to $94 \%$.(2) According to WHO, incidence is 5.35 per 10000 live births. $0.8 \%$ after previous lower segment caesarean section, (3) $>5 \%$ after classical caesarean section. Usually occurs during labour. It accounts for $5-10 \%$ of maternal deaths. (4) The term rupture uterus is used to denote a breach in the continuation of a gravid uterine musculature from any cause after foetal viability.(5) In uterine rupture, there occurs complete disruption of all uterine layers including the serosa. By comparison, uterine dehiscence generally refers to an incomplete uterine scar separation where the serosa remains intact. Most common cause of uterine rupture is the previous caesarean scar giving way, other causes are obstructed labour, injudicious use of oxytocics, previous myomectomy scar, uterine anomaly, direct trauma to the uterus, and rarely concealed abruption can also cause uterine rupture. Uterine rupture is associated with clinically significant uterine bleeding, foetal distress, expulsion or protrusion of foetus, placenta or both into abdominal cavity and the need for laparotomy and prompt delivery of the baby, uterine rent repair, or hysterectomy. The great enigma of diagnosis is the absence of any universal clinical features applicable to all varieties of uterine rupture. the best chance of detecting uterine rupture lies in careful and continuous monitoring of uterine contractions and foetal wellbeing during labour.(6) Continuous C.T.G. with intrauterine pressure measurements may help to identify scar rupture early and may be of value especially in those who have an oxytocin infusion.

Typically, uterine rupture occurs suddenly and requires immediate critical emergency care for mothers, foetuses or neonates. The strategies for prevention and management, as well as the quality of affordable care for women at risk of or experiencing uterine rupture, are likely to vary across settings depending on their diagnostic capacity, availability of obstetric interventions, and human and facility resources. (7) Identifying the high risk pregnancies for rupture uterus and their timely referral from grass root level is an important step in the secondary prevention, thereby improving the maternal and perinatal outcome. As rupture uterus is one of the preventable obstetrical complication, thus study was carried out for analysing the incidence of rupture uterus along with the various etiological factors, clinical aspects, maternal and foetal morbidity and mortality.

\section{METHODS}

This Descriptive study of rupture uterus was conducted over a period of 1 year from June 2017 to May 2018, in the department of obstetrics and gynecology, MKCG medical college, Berhampur, Odisha. All cases of rupture uterus, who were referred from periphery or who developed this complication in this hospital, were included in the study. Clinical records of 58 cases of rupture uterus out of 10080 deliveries during the study period were revived. Diagnosis were made by history and clinical examination and confirmed by laparotomy. The cases were analysed based on clinical presentation, complications, management and outcome. All patients and the babies were followed up till their discharge from the hospital.

\section{RESULTS}

Uterine rupture is one of the most catastrophic complication in obstetrics. Its incidence varies from $0.1 \%$ to $2.5 \%$ in different countries. The incidence of uterine rupture in our centre was $0.57 \%$. Previous caesarean section accounted for $74.14 \%$ of uterine rupture, that too in the lower segment (93.10\%). Subtotal/total hysterectomy was done in $68.97 \%$ cases and $31.03 \%$ cases were repaired. The maternal mortality was $5.17 \%$ Perinatal mortality was $94.83 \% 5.17 \%$ of cases were live birth, as these cases were accurately diagnosed, and prompt and timely management were taken.

\begin{tabular}{|c|c|c|}
\hline Total No. of Deliveries & Total No. of Cases & Incidence \\
\hline 10080 & 58 & $0.57 \%$ \\
\hline \multicolumn{3}{|c|}{ Table 1. Incidence } \\
\hline
\end{tabular}

\begin{tabular}{|c|c|c|}
\hline & Total No. of Cases & Percentage \\
\hline \multicolumn{3}{|l|}{ Age (Yrs.) } \\
\hline$<20$ & 0 & 0 \\
\hline $20-30$ & 42 & $72.42 \%$ \\
\hline$>30$ & 16 & $27.58 \%$ \\
\hline \multicolumn{3}{|l|}{ Parity } \\
\hline Primi & 0 & 0 \\
\hline Multi & 58 & $100 \%$ \\
\hline \multicolumn{3}{|c|}{ Socioeconomic status } \\
\hline Low & 56 & $96.55 \%$ \\
\hline High & 2 & $3.45 \%$ \\
\hline \multicolumn{3}{|l|}{ ANC } \\
\hline Booked & 56 & $96.55 \%$ \\
\hline Unbooked & 2 & $3.45 \%$ \\
\hline \multicolumn{3}{|l|}{ Residence } \\
\hline Urban & 4 & $6.90 \%$ \\
\hline Rural & 54 & $93.10 \%$ \\
\hline Table 2. & $\begin{array}{l}\text { of Rupture Uter } \\
\text { emographic Var }\end{array}$ & Regard to \\
\hline
\end{tabular}

Majority of the cases recorded were referred to our hospital, with diagnosis or diagnosed from here after admission (98.28\%) to labour room. One single case out of 58 incidence $(1.72 \%)$, developed rupture uterus in the hospital who were kept for trial of labour, where immediate interventions have been taken care of, to save the life of mother and baby.

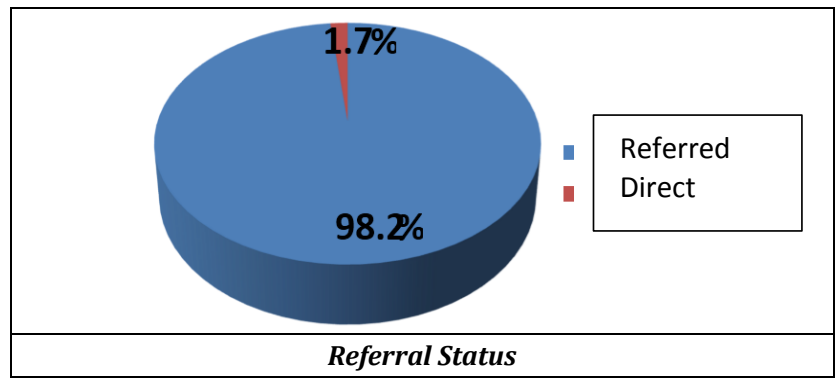

It was observed that previous caesarean section was the leading cause of rupture uterus (74.14\%), next common cause being prolonged labour $(10.34 \%)$, and obstructed labour (8.63\%). CPD constitutes $3.35 \%$ and malpresentations constitutes only $1.72 \%$. The adjuvant use of oxytocics and 
instrumental deliveries are of rare incidence, both constituting only $1.72 \%$.

\begin{tabular}{|c|c|c|c|}
\hline 1 & Previous LSCS & 43 & $74.14 \%$ \\
\hline & 1LSCS & 42 & $72.42 \%$ \\
\hline & 2LSCS & 1 & $1.72 \%$ \\
\hline 2 & Prolonged Labour & 6 & $10.34 \%$ \\
\hline 3 & Obstructed Labour & 5 & $8.63 \%$ \\
\hline 4 & CPD & 2 & $3.45 \%$ \\
\hline 5 & Malpresentations & 1 & $1.72 \%$ \\
\hline 6 & Labour & 1 & $1.72 \%$ \\
\hline & Oxytocin & 1 & $1.72 \%$ \\
\hline & PROSTAGLANDIN & 1 & $1.72 \%$ \\
\hline & Instrumental Delivery & Table 3. Risk Factors \\
\hline \multicolumn{3}{|c|}{} \\
\hline
\end{tabular}

It is evident that majority of cases of uterine rupture were of complete type $(82.76 \%)$ than incomplete type (17.24\%), mostly in the intrapartum period, incidence being (98.28\%). Only one case developed rupture uterus in the antepartum period, who was a grand multipara. The most common site of rupture of uterus noted was in the anterior wall (93.10\%). The posterior wall was involved in $6.90 \%$ of cases. Lower segment of uterus was involved in majority of cases, incidence being $(93.10 \%)$. Both upper and lower segment was involved in $3.45 \%$ of cases where one was a case of malpresentation, and one was a case of previous caesarean section. Most common associated complications noted were broad ligament hematoma (15.52\%), followed by bladder injury( $5.17 \%$ ). 1 patient developed colporrhexis, incidence being $1.72 \%$, who developed rupture uterus following obstructed labour, who was a multipara, referred to our hospital.

\begin{tabular}{|c|c|c|c|}
\hline & Findings & No. of Cases & Percentage \\
\hline \multirow[t]{3}{*}{1} & Type of Rupture & & \\
\hline & Incomplete & 10 & $17.24 \%$ \\
\hline & Complete & 48 & $82.76 \%$ \\
\hline \multirow[t]{3}{*}{2} & Timing of Rupture & & \\
\hline & Antepartum & 1 & $1.72 \%$ \\
\hline & Intrapartum & 57 & $98.28 \%$ \\
\hline \multirow[t]{3}{*}{3} & Site of Rupture & & \\
\hline & Anterior & 54 & $93.10 \%$ \\
\hline & Posterior & 4 & $6.90 \%$ \\
\hline \multirow[t]{4}{*}{4} & Segment of Uterus Involved & & \\
\hline & Upper & 2 & $3.45 \%$ \\
\hline & Lower & 54 & $93.10 \%$ \\
\hline & Both & 2 & $3.45 \%$ \\
\hline \multirow[t]{4}{*}{5} & Associated Complications & & \\
\hline & Broad ligament hematoma & 9 & $15.52 \%$ \\
\hline & Bladder injury & 3 & $5.17 \%$ \\
\hline & Colporrhexis & 1 & $1.72 \%$ \\
\hline & Table 4. Intr & tive Finding & \\
\hline
\end{tabular}

In majority of cases, hysterectomy was done (68.97\%), as these cases showed badly infected uterus, with ragged fibres. In 18 cases (31.03\%), uterine rent repair was done, and associated complications were also taken care of. Among them, tubal ligation was done in 10 cases.

\begin{tabular}{|c|c|c|}
\hline Methods & Total No. of Cases & Percentage \\
\hline $\begin{array}{c}\text { Uterine rent repair } \\
\text { with/without Sterilization }\end{array}$ & 18 & $31.03 \%$ \\
\hline $\begin{array}{c}\text { Subtotal/total } \\
\text { hysterectomy }\end{array}$ & 40 & $68.97 \%$ \\
\hline \multicolumn{2}{|c|}{ Table 5. Method of Surgical Management } \\
\hline
\end{tabular}

The perinatal mortality in cases of rupture uterus was very high (94.83\%). 3 cases were live birth among the 58 cases, of which 2 cases were diagnosed at the time of admission, who were referred here, and one case were kept for trial of labour and prompt and timely interventions have been taken to save the baby.
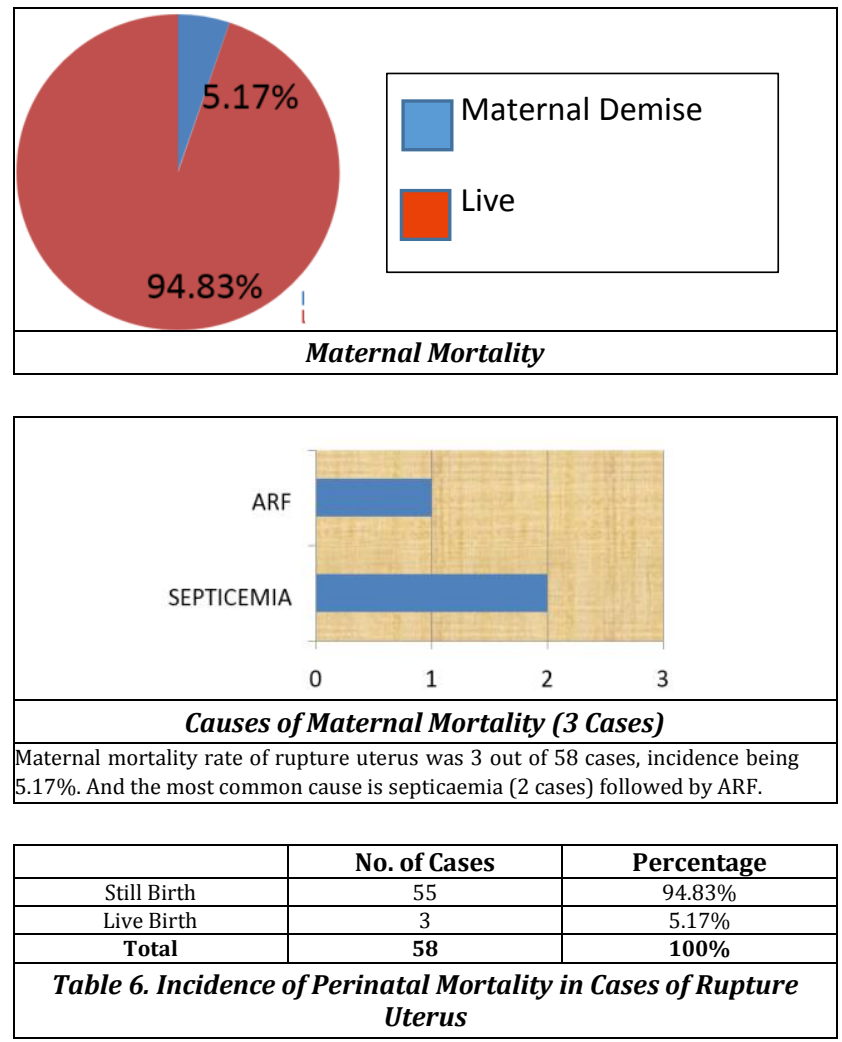

Most common post-operative complication noted were anaemia (68.97\%), and almost all 58 cases were transfused with more than 2 units of blood, either at the time of operation or post operatively. Febrile morbidity noted in $65.51 \%$ of cases. Other common complication noted were urinary tract infection (31.04\%), paralytic ileus (31.04\%) and respiratory tract infection (27.59\%). 20.69\% of patients developed shock and septicaemia. 2 patients developed acute renal failure, incidence $3.45 \%$, out of which one expired, and one recovered. 2 patients developed burst abdomen, whom needed secondary suturing later. 1 patient developed vesicovaginal fistula post operatively, who developed rupture uterus due to obstructed labour.

\begin{tabular}{|c|c|c|}
\hline Complications & No. of Cases & Percentage \\
\hline Anaemia & 40 & $68.97 \%$ \\
\hline Blood Transfusions >-2 & 58 & $100 \%$ \\
\hline Shock & 12 & $20.69 \%$ \\
\hline Febrile morbidity & 38 & $65.51 \%$ \\
\hline Paralytic ileus & 18 & $31.04 \%$ \\
\hline Septicaemia & 12 & $20.69 \%$ \\
\hline Peritonitis & 6 & $10.34 \%$ \\
\hline Burst abdomen & 2 & $3.45 \%$ \\
\hline Urinary tract infection & 18 & $31.04 \%$ \\
\hline Respiratory tract infection & 16 & $27.59 \%$ \\
\hline Acute renal failure & 2 & $3.45 \%$ \\
\hline Vesicovaginal fistula & 1 & $1.72 \%$ \\
\hline \multicolumn{2}{|c|}{ Table 7. Post-Operative Complications } \\
\hline \multicolumn{2}{|c|}{}
\end{tabular}

\section{DISCUSSION}

1. Uterine rupture is one of the most catastrophic complication in obstetrics. Its incidence varies from $0.1 \%$ to $2.5 \%$ in different countries.(7) The incidence of uterine rupture in our centre was $0.57 \%$. This was slightly more than the similar studies conducted by Sunanda N.(8) and other studies in India. The delay in timely referral, transportation difficulties from the remote areas, illiteracy, low socioeconomic status are some of the 
factors that contributing to the high incidence of rupture uterus.

2. Most of the cases occurred at the age group between 2030 yrs. (72.42\%), All of them were multipara (100\%), similar to the study(8) by Sunanda et al. The pathophysiological explanation of this may be the degree of myometrial fragility which is acquired with successive pregnancies.(9) Most of the cases were booked (96.55\%), but with minimal and irregular antenatal check-ups.

3. Uterine rupture occurs most frequently during labour, in our study incidence being $98.28 \%$.A tetrad of signs exist in theory in which acute abdominal pain, signs of shock, vaginal bleeding and deterioration of foetal heart rate are found in association. ${ }^{(9)}$ However all four aspects are only irregularly found together, and no women displayed all these clinical signs concurrently in my study.

4. In our study, previous caesarean section accounted for $74.14 \%$ of uterine rupture, that too in the lower segment (93.10\%). This was similar to the studies conducted by Malik HS and others.(10,11) Most of the cases were complete type, most frequent site is in the anterior wall of lower segment (93.10\%).

5. Subtotal/total hysterectomy was done in $68.97 \%$ cases and $31.03 \%$ cases were repaired. The decision for hysterectomy was taken on the basis of general condition of the patient, parity, no of living children and the extent of rupture.(12) This was against many of the studies conducted.(1,13) The bladder injury repaired was $5.17 \%$ similar to the study.(1)

The maternal mortality was $5.17 \%$ slightly less than the study by Rashmi et al.(13) Perinatal mortality was $94.83 \%$, which is similar to the study by Sahu $\mathrm{L}$ et al (1). $5.17 \%$ of babies were delivered alive, as they were admitted to hospital on time and those with incomplete rupture or rupture during their hospital stay as these cases were accurately diagnosed and prompt and timely management were taken. The high incidence of maternal and perinatal mortality due to the high incidence of referral to our hospitals, compared to other studies. The blood transfusion rate was $100 \%$, similar to study by Abdul Khadir Turgut Et al.(14)

\section{CONCLUSIONS}

Uterine rupture is a catastrophic but preventable complication. These cases should be properly assessed, and aggressive management should be initiated to save both mother and the baby. Over the years, there is decrease in the number of cases resulting from obstructed labour and unattended labours, but there is significant increase in previous caesarean section scar rupture. Reducing the primary caesarean section rate and optimising care for women with previous caesarean section will definitely decrease the incidence of rupture uterus. Emphasis should be given to educating the pregnant women and the relatives about the need for a carefully supervised and planned delivery in a wellequipped hospital during her subsequent pregnancies. More vigilant approach to prevent obstructed and prolonged labour, use of partograph, high index of suspicion and quick referral to a well-equipped centre are some of the factors that can help in reducing the incidence of rupture uterus. TOLAC should be conducted under vigilant care in a well-equipped and adequately staffed facility, where immediate caesarean delivery and advanced neonatal support are available.

\section{REFERENCES}

[1] Sahu L. A 10 year analysis of uterine rupture at a teaching institution. J Obstet Gynecol India 2006;56:502-6.

[2] Mahbuba, Alam IP. Uterine rupture-experience of 30 cases at Faridpur medical college hospital. Faridpur Med Coll J 2012;7(2):79-81.

[3] Hofmeyer GJ, Say L, Gulmezoglu AM. Systematic review: WHO systematic review of maternal mortality and morbidity: the prevalence of uterine rupture. BJOG: An International Journal of Obstetrics and Gynacology 2005;112(9):1221-8.

[4] Nahum GG, Pham KQ Uterine rupture in pregnancy. Obstetrics and Gynaecology May 12, 2010. emedicine.com. http//emedicine. Medscape. Com/ article/275854 over view.

[5] Misra R. Ian Donald's practical obstetric problems. $7^{\text {th }}$ edn. $7^{\text {th }}$ edn. New Delhi: Wolters \& Kluwer India Publications Pvt. Ltd., 2014: p. 591-6.

[6] Arunkumaran S, Chua S, Ratnam SS. Symptoms and signs with scar rupture - value of uterine activity measurements. Aust N Z J Obstet Gynacol 1992;32(3):208-12.

[7] Motomura K, Ganchimeg T, Nagata C, et al. Incidence and outcome of uterine rupture among women with prior caesarean section: WHO Multicountry Survey on Maternal and Newborn Health. Sci Rep 2017;7:44093. www.nature.com/scientificreports.

[8] Sunanda N, Priya R. A 2 year Analysis of uterine rupture in pregnancy. Int J Reprod Contracept Obstet Gynacol 2016;5(11):3983-6.

[9] Wang YL, Su TH. Obstetric uterine rupture of the unscarred uterus: a twenty year clinical analysis. Gunecol Obstet Invest 2006;62(3):131-5.

[10] Malik HS. Frequency, predisposing factors and foeto maternal outcome in uterine rupture. J Coll Physicians Surg Pak 2006;16(7):472-5.

[11] Gul A. Rupture of previously scarred uterus. Ann King Edward Med Coll 2004;10(4):573-5.

[12] Sunitha K, Indira I, Suguna P. Clinical study of rupture uterus - assessment of maternal and foetal outcome. IOSR-JDMS 2015;14(3):39-45.

[13] Rashmi, Radhkrishnan G, Valid NB, et al. Rupture uterus, changing Indian scenario. J Indian Med Assoc 2001;99(11):634-7.

[14] Turgut A, Ozler A, Evsen SM, et al. Uterine rupture revisited: predisposing factors, clinical features, management and outcomes from a tertiary care center in Turkey. Pak J Med Sci 2013;29(3):753-7. 